\title{
CANAIS DE INFORMAÇÃO DOS PESQUISADORES DA UNIVERSIDADE ESTADUAL DE PONTA GROSSA - PR
}

\author{
Ângela Maria de Oliveira \\ Ivani da Silva \\ Eunice Silva de Novais
}

\begin{abstract}
Resumo
Este estudo tem como objetivo identificar os canais de informação utilizados pelos pesquisadores da Universidade Estadual de Ponta Grossa (UEPG) - Paraná para atender suas necessidades informacionais. O estudo, de caráter exploratório, teve como instrumento de coleta de dados um questionário composto de perguntas abertas e fechadas, que foi dividido em três partes: a primeira levanta dados do perfil do pesquisador: a faixa etária, a categoria docente, a titulação e o regime de trabalho; a segunda informa sobre as atividades desenvolvidas pelos pesquisadores na UEPG e sobre a experiência profissional na instituição (ensino e pesquisa), além de outras; e a terceira, compreendendo informação e comunicação, trata sobre o comportamento dos pesquisadores em relação à busca da informação necessária para a realização de seus trabalhos; sobre os meios utilizados para atualização de conhecimentos e sobre a contribuição do Sistema de Bibliotecas da UEPG na comunicação científica dos pesquisadores. O questionário foi enviado eletronicamente para os 161 pesquisadores que estão distribuídos nos seguintes setores acadêmicos da UEPG: Setor de Ciências Agrárias e de Tecnologia; Setor de Ciências Exatas e Naturais; Setor de Ciências Humanas, Letras e Artes; Setor de Ciências Jurídicas; Setor de Ciências Sociais Aplicadas e Setor de Ciências
\end{abstract}

Biológicas e da Saúde. O estudo demonstra que os pesquisadores utilizam mais os canais informais, isto é, a Internet e os colégios invisíveis, bem como as bibliotecas virtuais são mais utilizadas do que as Bibliotecas do Sistema da UEPG. Conclui-se que é necessário atualizar o acervo de periódicos e melhorar a divulgação dos serviços oferecidos pelo Sistema de Bibliotecas da UEPG.

\section{Palavras-chave}

Canais de informação - Universidade Estadual de Ponta Grossa; Necessidades informacionais - Universidade Estadual de Ponta Grossa 


\section{INTRODUÇÃO}

A universidade é um espaço que possibilita a interação de diversas culturas, idéias e crenças, permitindo a produção do conhecimento através da pesquisa, do ensino e da extensão entre a comunidade universitária, principalmente entre os professores que atuam diretamente com a pesquisa, mas para desenvolver suas atividades científicas eles necessitam de uma comunicação eficaz que garanta a difusão e compartilhamento de seus resultados, bem como o acesso às fontes de informação. Com isso o presente estudo teve como objetivo verificar os canais de informação utilizados pelos pesquisadores da Universidade Estadual de Ponta Grossa para atenderem suas necessidades informacionais. A opção por estudar o pesquisador deu-se pelo fato de que "Apesar de maior parte da pesquisa científica e tecnológica brasileira estar sediada em instituições de ensino superior [...] tudo indica que os pesquisadores são um grupo bastante distinto do corpo docente no interior dessas instituições" (GUIMARÃES et al., 1995, p. 111112).

O estudo foi dividido em três partes: a primeira levanta o perfil do pesquisador quanto a faixa etária, a categoria docente, a titulação e o regime de trabalho; a segunda informa sobre as atividades desenvolvidas pelos pesquisadores na UEPG, sobre a experiência profissional na instituição (ensino e pesquisa), além de outras; e a terceira, fazendo uma abordagem sobre a informação e a comunicação, versa sobre o comportamento dos pesquisadores em relação à busca da informação necessária à realização de seus trabalhos; sobre os meios utilizados para atualização de conhecimentos e sobre a contribuição do Sistema de Bibliotecas da UEPG na comunicação científica dos pesquisadores.

$\mathrm{Na}$ literatura brasileira e estrangeira vários autores (ARAÚJO, 1979; BETTIOL, 1990; CHRISTOVÃO, 1979; DALLA ZEN, 1989; FARIA, 1986; GARVEY, 1979; GIACOMETTI; 1990; MEADOWS, 1999; MUELLER, 1994, 2000a, 2000b; RAMOS, 1994; TARGINO, 2000) discutem o processo de comunicação cientifica, no qual "Para sobreviver no mercado de trabalho ou para conviver com seus pares, os indivíduos são forçados a assimilar um corpo de conhecimento que se amplia a cada segundo" (TARGINO, 2000, p. 7).

Dessa forma torna-se importante verificar o quanto estes pesquisadores conhecem os serviços de informação e o quanto deles dependem e ainda, se eles atendem suas expectativas. Nesse contexto o bibliotecário deve estar envolvido no processo que propicia maior interatividade entre ele e o pesquisador fornecendo-lhe suporte no processo contínuo da busca de informação.

Com relação à interação do pesquisador com a biblioteca Dalla Zen (1989, p. 29) afirma: 
A descrição de como se processo a busca de informação, desde a identificação de necessidades individuais ou de grupos, os procedimentos de busca, bem como o uso que é feito dos dados assim obtidos, são essenciais para a criação, manutenção ou avaliação de serviços de informação científico-tecnológicos.

Enfatiza Kremer (1982, p. 66) "Os bibliotecários têm de conhecer seus usuários e reconhecer o fato de que suas demandas podem não corresponder a todas as suas necessidades".

Para tanto é importante realizar estudos que possam proporcionar subsídios para formulação e reformulação de serviços e produtos adequados às necessidades dos pesquisadores.

\section{CANAIS E FONTES DE INFORMAÇÃO}

Expõe Targino (2000, p. 10)

A comunicação científica é indispensável à atividade científica, pois permite somar os esforços individuais dos membros das comunidades científicas. Eles trocam continuamente informações com seus pares, emitindo-as para os seus sucessores e/ou adquirindo-as de seus predecessores. É a comunicação científica que favorece ao produto (produção cientifica) e aos produtores (pesquisadores) a necessária visibilidade e possível credibilidade no meio social em que produto e produtores se inserem.

\section{Porém}

[...] todos concordam que a formalização da comunicação científica resulta da necessidade de compartilhamento dos resultados das pesquisas entre o crescente número de cientistas, porquanto a ciência passa de atividade privada para uma atividade marcadamente social. Logo, o cientista isolado dá lugar ao pesquisador engajado na comunidade cientifica que exige competitividade e produtividade. A fim de que as novas informações e concepções formuladas tornem-se contribuições cientificas reconhecidas pelos pares, devem ser comunicadas de forma a favorecer sua comprovação e verificação, e a seguir, sua utilização em novas descobertas. (TARGINO, 2000, p. 18).

"Os pesquisadores, de forma geral, utilizam diversos meios para comunicar a seus pares suas descobertas, isto é, os resultados de suas investigações científicas na tentativa de comprovar a confiabilidade de suas idéias" (SOUTO, 2004, p. 17).

Witter (1990) salienta que a busca de informação representada pelas respostas às necessidades informacionais é uma característica no comportamento do pesquisador.

\begin{abstract}
A ampla exposição dos resultados de pesquisa ao julgamento da comunidade científica e sua aprovação por ela propicia confiança nesses resultados. Por essa razão, todos os trabalhos intelectuais de estudiosos e pesquisadores dependem de um intricado sistema de comunicação, que compreende canais formais e informais, os quais cientistas utilizam tanto para comunicar os resultados quanto para se informarem dos resultados alcançados por outros pesquisadores (MUELLER, 2000a, p. 21).
\end{abstract}

Para produzir ou disseminar informações entre a comunidade científica, os pesquisadores utilizam canais de comunicação, podendo esses ser formais, semi- 
formais, informais e intermediários (ROSEMBERG, 2000).

Araújo (1991, p. 39) corrobora a idéia de Mueller (2000a) ao afirmar: "O sistema global de informação técnico-científica utiliza fundamentalmente dois canais básicos de comunicação, que são apresentados no seguinte contexto: os canais formais ou baseados na literatura e os canais informais ou pessoais."

Meadows também divide os canais de informação em dois tipos: formal e informal. Graças a eles
Os meios formais são acessíveis de forma fixa por um longo período, e sua aquisição não requer, normalmente, contato com o autor. Livros e periódicos apresentam-se como exemplos típicos deste meio de comunicação. Os canais formais constituem-se de meios de comunicação escritos, quais sejam: livros, periódicos, relatórios, boletins, índices, abstracts (2000, p. 25).

Souto (2004) também divide o sistema de comunicação cientifica em: canais de comunicação formais e informais, conforme figura 1. Neles o pesquisador além de ser o produtor da informação é também seu consumidor.

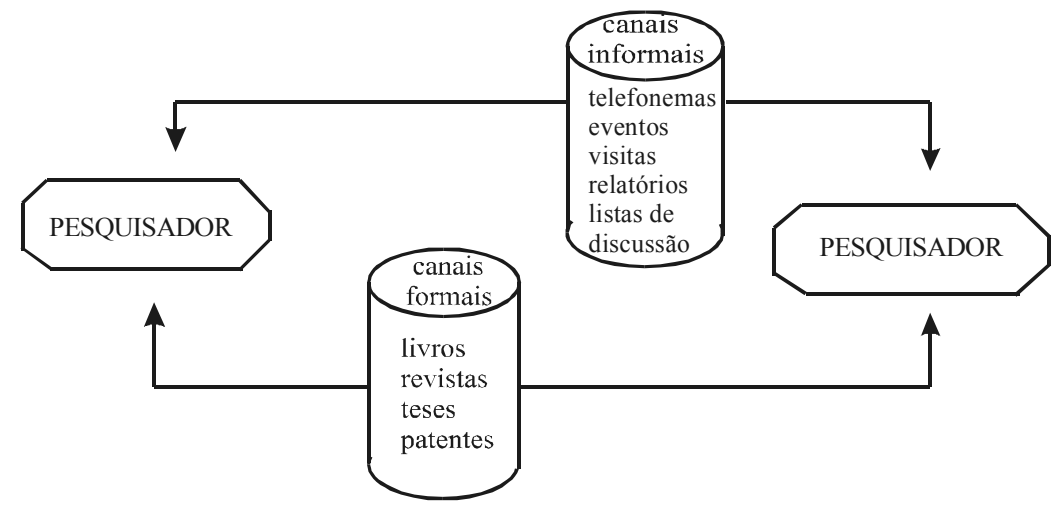

Figura 1 - Sistema de Comunicação Científica Fonte: Souto (2004, p. 19)

Targino apresenta as diferenças entre os canais formais e informais (quadro 1). Para a autora:

Ambos são indispensáveis à comunicabilidade da produção científica, mas são utilizados em momentos diversos e obedecem a cronologias diferenciadas. A disseminação através de canais informais precede a finalização de projeto de pesquisa e até mesmo o inicio de sua execução, pois há propensão para se abandonar um projeto, quando os pares não demonstram interesse. Em contrapartida, a trajetória da comunicação formal é demorada. (2000, p. 19).

\begin{tabular}{|l|l|}
\hline \multicolumn{1}{|c|}{ CANAIS FORMAIS } & \multicolumn{1}{c|}{ CANAIS INFORMAIS } \\
\hline Público potencialmente grande & Público restrito \\
\hline Informação armazenada e recuperável & Informação não armazenada e não recuperável \\
\hline Informação relativamente antiga & Informação recente \\
\hline Direção do fluxo selecionada pelo usuário & Direção do fluxo selecionada pelo produtor \\
\hline Redundância moderada & Redundância, às vezes, significativa \\
\hline Avaliação prévia & Sem avaliação prévia \\
\hline Feedback irrisório para o autor & Feedback significativo para o autor \\
\hline
\end{tabular}

Quadro 1 - Distinções básicas entre os canais formais e informais de comunicação Fonte: TARGINO (2000, p. 19) 
Para Back (1972), os canais de informação são classificados da seguinte forma:

a) canais formais - livro -texto, artigos de periódicos, manuais, revisões, trabalhos de congressos, índices e bibliografias, abstracts, catálogos de bibliotecas, meios audiviosuais;

b) canais semi-formais - teses e relatórios não publicados, catálogos de fornecedores, manuscritos e periódicos comerciais;

c) canais informais - discussões pessoais, chamadas telefônicas, correspondência privada, encontros locais e seminários.

Segundo Dalla Zen (1989, p. 37) as vantagens dos canais informais são: "informação corrente, disseminando de forma seletiva o conhecimento, eliminando os itens irrelevantes e direcionando a pesquisa". A autora considera como desvantagens "os fatos de que as informações disponíveis se constituem em dados incompletos, bem como o de que poucas pessoas têm acesso a elas". Em relação aos canais formais a autora menciona como vantagens: "elas podem se esforçar para cobrir tudo dentro de uma área, serem públicas e acessíveis, além de permanentes, já que envolvem um registro". Como desvantagens: "a publicação e o aparecimento em alguma fonte, e, ainda, seu formato ser fixado e igual para todos os usuários".
Guedes e Barros (1993, p. 46, grifo dos autores) salientam que nos "Canais informais de comunicação [...] a transferência da informação ocorre via contatos interpessoais, através da comunicação oral [...] redes eletrônicas [...] e de quaisquer outros recursos destituídos de formalismo [...] como reuniões científicas ou [...] colégios invisíveis, clubes profissionais". Os autores seguem afirmando: "A comunicação informal não é privilégio de nenhuma área específica do conhecimento, constituindo-se aliada indispensável à produção cientifica em sua ampla acepção" (p. 48).

A grande vantagem da comunicação informal para Gusmão (1987) é a possibilidade de maior atualização e sua rapidez. Para o autor, a armazenagem e recuperação da informal, o acesso a ela e sua disseminação são as desvantagens da comunicação informal.

Araújo (1979) corrobora a idéia de Gusmão (1987) ao considerar que os canais informais são mais rápidos do que os formais.

Para Guedes e Barros (1993, p. 49, grifos dos autores)

a comunicação informal é mais flexível do que a formal tendo maior dinamicidade e fluidez, o que permite obter mais informações, em contraposição ao que ocorre por vias formais. Ademais recebe controle direto dos usuários, enquanto a formal é controlada, exclusivamente, por especialistas. 
Com relação às fontes de informação, Dalla Zen (1989) as dividem em três tipos:

a) privadas - armazenadas na memória e em arquivos pessoais;

b) organizacionais - armazenadas por colegas, supervisores, documentos internos;

c) externas - todas as demais fontes.

Souto (2004, p. 20-21), do ponto de vista das funções, divide as fontes de informação em:

a) fontes primárias - registram informações originais (novas) ou novas interpretações de fatos/idéias já conhecidos. O conteúdo não foi assimilado pela comunidade científica. Exemplo: teses, artigos de periódicos, relatórios técnicos, patentes, normas técnicas e anais de congressos;

b) fontes secundárias: facilitam 0 uso do conhecimento disperso nas fontes primarias, filtram e organizam a informação de acordo com um arranjo definido. Exemplos: dicionários, enciclopédias, livros, anuários, monografias, tabelas, manuais, tratados;

c) fontes terciárias: facilitam a localização das fontes primárias e terciárias [sic]. Exemplo: bibliografias, periódicos de indexação e resumo, catálogos coletivos e diretórios.

Souto (2004) ilustra "a relação das categorias das fontes de informação, a partir de sua função", na figura 2.

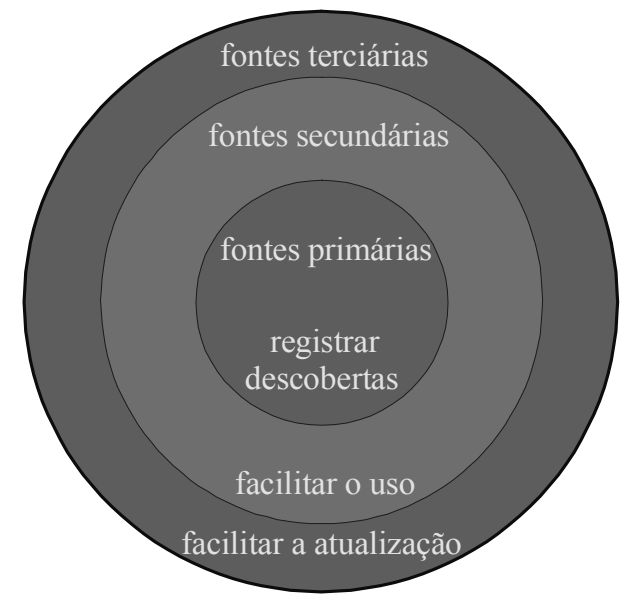

Figura 2 - Divisão das fontes de informação a partir de suas funções

Fonte: Souto (2004, p. 21)

\section{METODOLOGIA}

Este estudo de caráter exploratório incluiu a população de pesquisadores da Universidade Estadual de Ponta Grossa $\mathrm{PR}$, tendo como base a lista dos 161 pesquisadores com projetos de pesquisa em andamento fornecida pela Pró-Reitoria de Pesquisa e Pós-Graduação-PROPESP em abril de 2004.

$\mathrm{O}$ instrumento de coleta de dados utilizado para a pesquisa foi um questionário com perguntas abertas e fechadas, que foi dividido em três partes: a primeira levanta o perfil do pesquisador quanto a faixa etária, a categoria docente, a titulação e o regime de trabalho; a segunda informa sobre as atividades desenvolvidas pelos pesquisadores na UEPG, sobre a experiência profissional na instituição (ensino e pesquisa), além de outras; e a terceira, fazendo uma abordagem sobre a informação e a comunicação, versa sobre o comportamento dos pesquisadores em relação à busca 
da informação necessária à realização de seus trabalhos; sobre os meios utilizados para atualização de conhecimentos e sobre a contribuição do Sistema de Bibliotecas da UEPG na comunicação científica dos pesquisadores.

O questionário foi enviado eletronicamente e a devolução foi pela forma mais conveniente ao entrevistado: por meio eletrônico ou entregue em qualquer biblioteca do sistema até 06 de junho de 2004. Dos 161 questionários enviados foram recebidos 40 , representando retorno de $24,8 \%$ do total enviado.

\section{RESULTADOS}

Visando estabelecer o perfil dos pesquisadores entrevistados buscou-se identificar faixa etária, categoria docentes, titulação e regime de trabalhos dos mesmos.

Com relação à faixa etária dos pesquisadores, a Tabela 1 demonstra que o corpo de pesquisadores da UEPG pode ser considerado "jovem", estando $35 \%$ dos pesquisados na faixa de 35 a 39 anos e $20 \%$ entre 40 e 44 anos. Esses dados confirmam estudos realizados, conforme afirma Hajos (1979 apud GUEDES, 1993, p.54) “...é precisamente após a idade de 35 anos quando a maioria dos pesquisadores começa a dar melhores contribuições nos campos técnicos-científicos". O fato pode estar relacionado com a criação de novos cursos e a realização de concursos o que pode ter atraído profissionais de outros locais.

Tabela 1 - Faixa etária dos pesquisadores 2004

\begin{tabular}{l|l|l}
\hline Faixa Etária & F & \% \\
\hline 30 a 34 anos & 6 & 15 \\
\hline 35 a 39 anos & 14 & 35 \\
\hline 40 a 44 anos & 8 & 20 \\
\hline 45 a 49 anos & 6 & 15 \\
\hline 50 a 54 anos & 3 & 7,5 \\
\hline 55 a 59 anos & 3 & 7,5 \\
\hline Total & $\mathbf{4 0}$ & $\mathbf{1 0 0}$ \\
\hline
\end{tabular}

Quanto à categoria docente os dados demonstraram que $25 \%$ dos pesquisadores são professores assistentes; $60 \%$ adjuntos e $18 \%$ associados; quanto ao nível de escolaridade, $17,5 \%$ são mestres; $70 \%$ doutores; $5 \%$ estão em processo de doutoramento e pós-doutoramento; $2,5 \%$ dos pesquisados dos pesquisados não informaram o nível de escolaridade. No regime de trabalho de Tempo Integral Dedicação Exclusiva - TIDE estão inscritos $87,5 \%$ dos pesquisadores, e no regime de 20 horas e 40 horas respectivamente $2,5 \%$ e $10 \%$ dos pesquisados.

No que se refere às atividades exercidas pelos pesquisadores $27,5 \%$ trabalha com pesquisa, graduação e pós-graduação.

O que se observa na Tabela 2 é um número expressivo de pesquisadores que exercem também a atividade na administração universitária (40\%). Destes alguns responderam que são coordenadores de cursos e chefes de departamento. 
Tabela 2 - Atividades Exercidas pelos Pesquisadores na UEPG - 2004

\begin{tabular}{l|c|c}
\hline \multicolumn{1}{c|}{ Atividades } & F & $\%$ \\
\hline Ensino / Graduação / Pós-Graduação / Pesquisa/ & 11 & 27,5 \\
\hline Ensino / Graduação / Pesquisa / Extensão & 7 & 17,5 \\
\hline Ensino / Graduação / Pesquisa / Administração Universitária & 5 & 12,5 \\
\hline Ensino / Graduação / Pesquisa & 5 & 12,5 \\
\hline $\begin{array}{l}\text { Ensino / Graduação / Pós-Graduação / Pesquisa / Administração Univer- } \\
\text { sitária }\end{array}$ & 4 & 10 \\
\hline $\begin{array}{l}\text { Ensino / Graduação / Pós-Graduação / Pesquisa / Extensão / Adminis- } \\
\text { tração Universitária }\end{array}$ & 3 & 7,5 \\
\hline Ensino / Graduação / Pesquisa / Extensão / Administração Universitária & 4 & 10 \\
\hline $\begin{array}{l}\text { Outra(S). Especificar - Secretaria do Emprego, Trabalho e Promoção } \\
\text { Social }\end{array}$ & 1 & 2,5 \\
\hline Total & 40 & 100 \\
\hline
\end{tabular}

O estudo revela que, embora $87,5 \%$ dos pesquisadores tenham dedicação exclusiva, eles ainda estão muito envolvidos com administração universitária, o que traz como conseqüência dificuldade para o aumento da produção científica.

Foi solicitado aos pesquisadores que registrassem o tempo de experiência tanto no ensino como na pesquisa. Verificou-se que :

a) até dois anos de experiência em pesquisa e ensino (2 respostas); com até dois anos de experiência em pesquisa e mais de 15 anos em ensino (1 resposta); até dois anos de experiência em pesquisa e de 11 a 15 anos em ensino (1 resposta); até dois anos de pesquisa e de 3 a 6 anos em ensino (3 respostas);

b) de 3 a 6 anos em pesquisa e ensino (7 respostas);

c) de 7 a 10 anos em pesquisa e ensino (11 respostas); com 7 a 10 anos em pesquisa e de 11 a 15 anos em ensino (4 respostas); de 7 a 10 anos em pesquisa e mais de 15 anos em ensino (5 respostas);

d) de 11 a 15 anos em pesquisa e ensino (4 respostas); com 11 a 15 anos em pesquisa e mais de 15 anos em ensino (1 resposta);

e) mais de 15 anos em pesquisa e ensino (1 resposta).

Em se tratando de recursos destinados ao desenvolvimento dos projetos de pesquisa, para $30 \%$ dos pesquisados os recursos são próprios e para $70 \%$ são de terceiros. A fonte mais citada é o CNPq , também foi mencionado: CAPES, Fundação Araucária, FINEP, Paraná Tecnologia, Paranatur, Convênio com Prefeitura Municipal de Ponta Grossa e Núcleo Regional de Educação (Ponta Grossa).

Os dados demonstram a importância dos projetos desenvolvidos na UEPG que justificam o aporte de recursos das principais agências de fomento.

Dos pesquisados $20 \%$ estão realizando pesquisa individualmente, $20 \% \mathrm{em}$ grupo e $60 \%$ individualmente e em grupo. 
Com o estudo pretendeu-se também identificar a existência de uma rede de comunicação ou um colégio invisível entre os pesquisadores. Os contatos elencados foram:

a) pesquisadores da UEPG;

b) pesquisadores de outras instituições nacionais;

c) pesquisadores de outras instituições estrangeiras;

d) pesquisadores de outras áreas.

Foram apresentados quatro graus de freqüência que variaram de alta freqüência a nula. Os contatos mencionados como de alta freqüência foram com colegas de outras instituições nacionais (52,5\%). Quanto ao contato com pessoas de outras instituições estrangeiras $37,5 \%$ afirmou que mantém freqüentemente contato, $15 \%$ alta freqüência e 27,5\% nenhuma.

Com relação aos contatos com pesquisadores da própria instituição os dados foram: freqüentemente - $27,5 \%$, alta freqüência - 32,5\%, conforme gráfico 1.

Mueller (1994, p. 41) enfatiza que as pesquisas estimuladas nas universidades, na graduação ou na pós-graduação, geram avanços científicos e tecnológicos. A natureza cumulativa da ciência faz com que a comunicação entre cientistas seja absolutamente essencial ao seu desenvolvimento.
Em pesquisa realizada por Sampaio (2000), 80\% dos pesquisadores participam de discussões informais com colegas do departamento e $60 \%$ em discussão com colegas de outras instituições.

Pelos dados do gráfico 1 confirma-se que cada vez mais os pesquisadores estão agilizando a troca de informações mantendo contato com outros pesquisadores de sua área. Pela internet a comunicação entre os pesquisadores foi incrementada assegurando rapidez na troca de informações entre os pares. Essa assertiva pode ser confirmada na pesquisa realizada por $\mathrm{Pi}$ nheiro (2003) que ao procurar saber sobre os objetivos dos pesquisadores quando usam a internet para fins de atividades científicas, verificou-se que $96,4 \%$ deles a utilizam para a comunicação científica entre seus pares, ou seja, para prática do colégio invisível.

Colégio invisível, de acordo com Mueller (1994, p. 310), não são grupos formais, bem definidos e identificados, mas simplesmente um grupo de pesquisadores que está, em um dado momento, trabaIhando em torno de um mesmo problema ou área de pesquisa e se comunica sobre o andamento das pesquisas. 


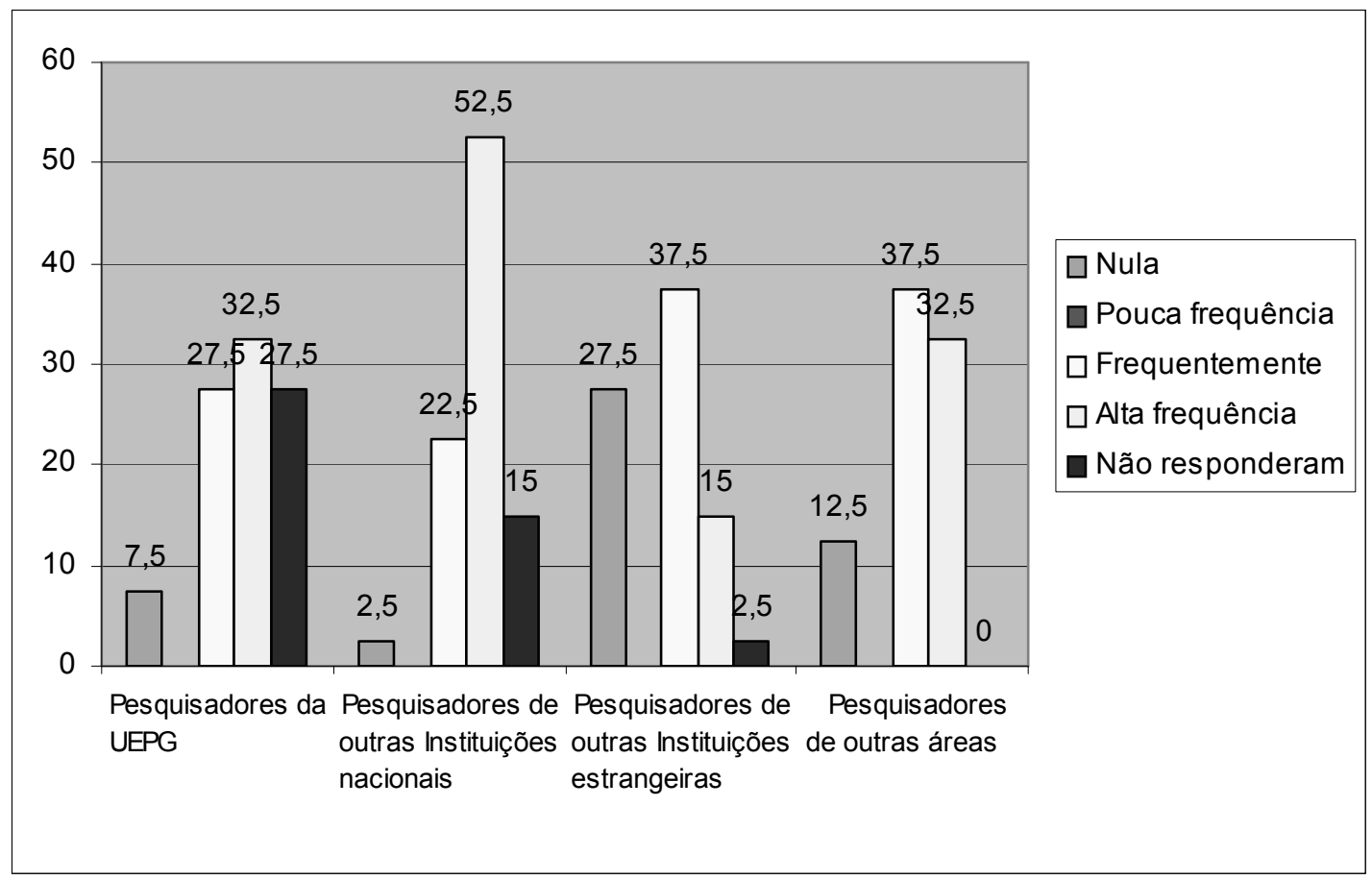

Gráfico 1 - Rede de Comunicação dos Pesquisadores - 2004

Merton e Gaston (1977 apud MUELLER, 1994, p. 310) expõem que os "colégios invisíveis podem ser sociologicamente percebidos como grupos de cientistas, geograficamente dispersos que trocam informações entre si com mais freqüência do que com os outros cientistas integrantes da comunidade científica".

Para Guedes e Barros (1993, p. 51) os colégios invisíveis são considerados "grupos fechados, [..] [que] dispensam institucionalização e representam a forma como os pesquisadores, voluntariamente, têm se organizado, com a finalidade de intercambiar conhecimentos."

Acosta Hoyos (1980 apud GUEDES; BARROS, 1993, p. 51-52) menciona os objetivos dos colégios invisíveis, que são: estimular comunicação pessoal entre pesquisadores da mesma área, tanto em âmbito nacional como internacional;

evitar a duplicação de pesquisas similares;

facilitar a organização de núcleos de comunicação cientifica, em nível microorganizacional;

aproveitar a capacidade e o potencial dos cientistas mais experientes;

incentivar as novas gerações de pesquisadores mediante o compartilhamento de descobertas e dados;

facilitar o contato direto, a fim de facilitar o avanço de pesquisas em andamento;

permitir um fluxo contínuo de transferência de informações técnico-científicas.

Percebe-se que os membros do "colégio invisível" são profissionais que se dedicam à mesma área de conhecimento "co- 
legas ou rivais, espalhados pelo mundo com vínculos não formais", mas que interagem entre si em prol da ciência.

No intuito de detectar possíveis relações sociais em áreas de pesquisa da UEPG, perguntou-se aos pesquisadores se eles mantinham algum tipo de intercâmbio com instituições técnico-científicas no Brasil e/ou no exterior. Dos pesquisados 55\% mantêm intercâmbio. As instituições mais citadas foram: UNICAMP, UFPR, USP, UFSCAR e UFRGS. Foram indicados, ainda, contatos com pessoas de universidades estrangeiras, como: La Trobe University, Austrália.

O estudo procurou identificar também quais são os fatores importantes que influenciam os pesquisadores na escolha das fontes de informação. Nesse caso, foram relacionados os seguintes fatores: localização próxima; informações escritas em idioma conhecido; relevância das respostas às necessidades de informação; autor conhecido; editor com credibilidade, recomendação feita por pessoa de confiança.

Os fatores citados pelos pesquisadores como mais importantes foram: relevância das respostas às necessidades de informação e a localização próxima das fontes de informação. Os fatores menos importantes foram: fontes de informação recomendadas por pessoas de confiança e escritas por autor desconhecido.

Em estudo realizado pelas autoras Rodrigues e Vilas Boas (1993) verificou-se que os fatores relevância e localização próxima obtiveram $79 \%$ e $45 \%$ respectivamente de respostas. Tais dados corroboram a credibilidade da pesquisa, deixando claro que a acessibilidade é fundamental para os pesquisadores.

Em Sampaio (2000), o fator que mais influencia na escolha do canal de comunicação é a atualidade $(95,6 \%)$ seguido do fator confiabilidade $(82,2 \%)$ e relevância do tema pesquisado (80\%). O estudo possibilitou que, para divulgar suas pesquisas, $80 \%$ dos pesquisadores mencionaram como fator de mais influência: maior difusão, penetração na comunidade cientifica, seguido do fator obter maior reconhecimento profissional, que foi citado por $71,1 \%$ dos pesquisadores.

Quanto à utilidade das Fontes de Informação nas suas pesquisas, foram relacionadas 35 fontes de informação, incluindo-se revistas técnico-científicas nacionais, estrangeiras, teses / dissertações / monografias, e-mail e relatórios de pesquisa. Indicaram-se cinco graus de utilidade, variando de muito útil até não utiliza. Solicitouse ao pesquisador que atribuísse um deles a cada uma das fontes relacionadas.

Constatou-se que a internet é, para $80 \%$ dos pesquisadores, muito útil. As demais tecnologias (e-mails $(52,5 \%)$, listas de discussão $(27,5 \%)$, chats $(7,5 \%)$ foram consideradas muito úteis, assumindo o email, cada vez mais, papel importantíssimo na comunicação. Esses dados reforçam a 
importância da rede no ambiente da comunicação científica, facilitando o acesso aos recursos informacionais na rede, possibilitando a geração de novos conhecimentos, o contato entre pesquisadores de países diferentes até mesmo para publicar livros e/ou artigos em parceria. Ou seja, a internet além de permitir a troca de informações permite também acesso a vários serviços de informação. Nesse aspecto ressalta Souza (2003, p. 135) "A comunicação interpessoal tornou-se mais ágil e foi ampliada a disponibilidade de informação pelo acesso às bibliotecas virtuais de todo o mundo".

Andreessen (2001, p. 8) assegura que o e-mail continua sendo o aplicativo mais importante da internet, um canal que incentiva a comunicação informal e proporciona aos pesquisadores maior interatividade com seus pares.

Giraldes (2001, p. 16) afirma:

o avanço das tecnologias de informação e comunicação tem possibilitado novas formas de comunicação científica, modificando significativamente o fluxo de informação. Este avanço possibilitou o surgimento da comunicação eletrônica, que veio modificar de forma efetiva os procedimentos de busca e recuperação da informação.

Russell (2000 apud GIRALDES, 2001, p. 17) salienta

uma das questões mais importantes no atual ambiente em expansão da comunicação eletrônica é o efeito que as novas tecnologias de informação estão tendo sobre a vida profissional dos cientistas dos países periféricos, isto é, cientistas de paises em desenvolvimento. $\mathrm{O}$ autor esclarece que o isolamento dos centros de periferia nem sempre é resultado de preferências ou níveis intelectuais distintos; a falta de tecnologia da comunicação e de acesso à informação também resulta em marginalidade.

Em sua pesquisa Vieira (apud PINHEIRO, 2003) elencou os índices de uso, vantagens e desvantagens do correio eletrônico na comunicação técnicocientífica da Embrapa. Nessa pesquisa alguns pesquisadores consideram a rede como um recurso para minimizar distâncias geográficas, "o que é um fator considerável em países de dimensões continentais como o Brasil" (PINHEIRO, 2003).

Archambault (1995 apud PINHEIRO, 2003) destaca

a dispersão geográfica favorece a utilização da rede. No caso de comunicação intra-institucional, devemos chamar a atenção para a situação mencionada, de instituições de âmbito nacional, porque, assim, pesquisadores de regiões periféricas aos grandes centros são muitos beneficiados com esse recurso.

Além da internet, o livro estrangeiro foi considerado por $67,5 \%$ como muito útil, a revista técnico-científica estrangeira, a revista técnico-científica nacional, respectivamente com $65 \%$ e $60 \%$ também foram consideradas muito úteis.

Em pesquisa realizada por Guedes e Barros (1993), a fonte mais utilizada pelos docentes da Universidade Federal do Piauí são livros, manuais e folhetos nacionais. 
Seguido por revistas e jornais nacionais especializados.

Ziman (1968 apud DIAS, 1999) asse-

vera

a revista cientifica [...] tem um papel importantíssimo na disseminação da literatura cientifica, por seu caráter de publicação regular, proporcionando divulgação rápida e garantida dos resultados de um número maior de pesquisas que, se tomadas separadamente, não teriam grande significação, mas que, ao serem reunidas umas às outras, são capazes de estimular novos trabalhos e promover avanços científicos.

Afirma Ziman (apud PRAZERES, 1989, p. 29)

as únicas instituições da comunidade científica que têm força e uma base sólida são as suas revistas especializadas. Concentrando-se unicamente na plausibilidade e importância da argumentação apresentada [...], o sistema de julgamento instituído por elas oferece a única garantia de manutenção dos padrões científicos [...].

Explica Dias (1999) que o periódico científico, além de sua função principal de comunicação entre os pares da comunidade científica na busca de informações e de seu reconhecimento e prestígio, também atua como registro público da informação, relacionado à prioridade e à propriedade das descobertas científicas.

$O$ autor segue afirmando:

O periódico é considerado o arquivo oficial da comunidade científica, já que a avaliação e crítica prévias, por editores e bancas de especialistas, dos textos submetidos à pu- blicação, considerando a plausibilidade e a importância da argumentação, sem nenhuma deferência especial à identidade do autor ou da empresa para a qual trabalha, Ihe conferem uma base mais sólida para a ciência (DIAS, 1999).

Com relação às atuais funções do periódico científico, a Royal Society (apud MUELLER, 2000b, p. 75-76) aponta quatro, que são: 1) comunicação formal dos resultados da pesquisa original par a comunidade cientifica e demais interessados; 2) preservação do conhecimento registrado; 3) estabelecimento da propriedade intelectual; e 4) manutenção do padrão de qualidade na ciência.

A autora destaca ainda os problemas enfrentados pelo periódico científico. São eles:

demora na publicação do artigo que, às vezes, chega a ser de um ano após o recebimento do original pelo autor;

custos altos na aquisição e manutenção de coleções atualizadas; rigidez do formato impresso em papel, quando se compara com a versatilidade dos formatos eletrônicos;

dificuldade para o pesquisador, em saber o que de seu interesse está sendo publicado, pis são muitos os periódicos e pouco eficientes os instrumentos de identificação e busca;

dificuldade para o pesquisador ter acesso a artigos que lhe interessam, pis mesmo sabendo que um novo artigo de seu interesse foi publicado, nem sempre sua biblioteca assina o periódico que o publicou ou consegue obter copia desse artigo com a rapidez suficiente. (MUELLER, 2000b, p. 76-77) 
Em pesquisa realizada por Giraldes (2001) verificou-se que, entre o uso de canais formais e informais de comunicação científica, os docentes/pesquisadores utilizam expressivamente livros, periódicos científicos impressos e eletrônicos, eventos científicos e a Internet.

Como afirma Prazeres (1989, p. 24):

No decorrer das várias etapas da sua pesquisa, o produtor de informação prossegue disseminando e discutindo seu trabalho através de reuniões locais e eventos científicos nacionais e internacionais, ampliando as perspectivas de ter o seu produto analisado, avaliado e absorvido pelos pares envolvidos e interessados nos mesmos problemas científicos.

Sampaio (2000) detectou em sua pesquisa que $95,5 \%$ dos pesquisados utilizam revistas especializadas estrangeiras $e$ $88,8 \%$ livros "como insumo para suas pesquisas."

Refere Mueller (2000a, p. 23) "A comunicação formal utiliza-se de canais de formais, como são geralmente chamadas às publicações com divulgação mais ampla, como periódicos e livros. Dentre esses últimos, o mais importante para a ciência são os artigos publicados em periódicos científicos".

Entre as fontes apontadas como de pouca utilidade, encontram-se os catálogos de produtos e equipamentos, relatórios não publicados, livros nacionais, conforme demonstram os dados da Tabela 3.

Com relação ao uso de bibliotecas para localização das fontes de informação verificou-se que as bibliotecas virtuais são as mais utilizadas.

Os resultados obtidos evidenciaram que o Sistema de Bibliotecas da UEPG, é freqüentado mensalmente pelos pesquisadores nos seguintes níveis: nunca $-15 \%$; $1-2$ vezes $-42,5 \%$; $3-4$ vezes $-22,5 \%$; $5-6$ vezes $-5 \%$ e mais de 7 vezes $-10 \%$ num universo em que $5 \%$ dos pesquisadores preferiram não responder à questão.

Para $7,5 \%$ dos pesquisados, nunca foi necessário buscar informações em bibliotecas de outras instituições, mas para $40 \%$ isso foi necessário pelo menos de 1-2 vezes durante o mês. Verificou-se que, na escala de 3-4 vezes e de 5-6 vezes, tendem a freqüentar mensalmente a Biblioteca de outras instituições em torno de $15 \%$ e $7,5 \%$ dos pesquisadores, respectivamente, enquanto $12,5 \%$ deles dizem recorrer a elas mais de 7 vezes por mês.

No que tange à utilização de biliotecas particulares, observa-se que o percentual dos que as usam mais de 1-2 vezes ao mês reduz-se para $27,5 \%$, inferior ao daqueles que usam outros tipos de bibliotecas. 
Tabela 3 - Graus de utilidade atribuídos às Fontes de Informação pelos pesquisadores da UEPG -2004

\begin{tabular}{|c|c|c|c|c|c|c|c|c|c|c|c|c|c|c|}
\hline \multirow[t]{2}{*}{ Fontes de Informação } & \multicolumn{2}{|c|}{ Muito Útil } & \multicolumn{2}{|c|}{ Útil } & \multicolumn{2}{|c|}{$\begin{array}{l}\text { Utilidade } \\
\text { Regular }\end{array}$} & \multicolumn{2}{|c|}{\begin{tabular}{|c|} 
Pouca \\
Utilidade
\end{tabular}} & \multicolumn{2}{|c|}{\begin{tabular}{|c|} 
Não \\
Utiliza
\end{tabular}} & \multicolumn{2}{|c|}{\begin{tabular}{|c|} 
Sem \\
Informacao
\end{tabular}} & \multicolumn{2}{|c|}{ Total } \\
\hline & $\mathrm{n}^{\circ}$ & $\%$ & $n^{\circ}$ & $\%$ & $\mathrm{n}^{0}$ & $\%$ & $\mathrm{n}^{0}$ & $\%$ & $\mathrm{n}^{\circ}$ & $\%$ & $\mathrm{n}^{\circ}$ & $\%$ & & $\%$ \\
\hline Anais de Congresso e similares & 19 & 47,5 & & 27,5 & 6 & 15 & 4 & 10 & 0 & 0 & 0 & 0 & & 100 \\
\hline Arquivo Pessoal & 18 & 45 & 17 & 42,5 & 1 & 2,5 & 2 & 5 & 0 & 0 & 2 & 5 & 40 & 100 \\
\hline Banco de Dados & 19 & 47,5 & 12 & 30 & 3 & 7,5 & 1 & 2,5 & 1 & 2,5 & 4 & 10 & 40 & 100 \\
\hline Bibliotecas & 23 & 57,5 & 11 & 27,5 & 3 & 7,5 & 2 & 5 & 0 & 0 & 1 & 2,5 & & 100 \\
\hline Boletins Técnicos & 10 & 25 & 10 & 25 & 9 & 22,5 & 4 & 10 & 3 & 7,5 & 4 & 10 & 40 & 100 \\
\hline Catálogo de Fabri & 2 & 5 & 10 & 25 & 10 & 25 & 8 & 20 & 7 & 17,5 & 3 & 7,5 & 40 & 100 \\
\hline Catálogo de Livrarias e Editoras & 5 & 12,5 & 12 & 30 & 9 & 22,5 & 6 & 15 & 3 & 7,5 & 5 & 12,5 & & 100 \\
\hline Catálogo de Prod & 2 & 5 & 10 & 25 & 6 & 15 & 10 & 25 & 6 & 15 & 6 & 15 & 40 & 100 \\
\hline Chats & 3 & 7,5 & 4 & 10 & 6 & 15 & 5 & 12,5 & 17 & 42,5 & 5 & 12,5 & 40 & 100 \\
\hline Contato & 10 & 25 & 16 & 40 & 8 & 20 & 3 & 7,5 & 1 & 2,5 & 2 & 5 & 40 & 100 \\
\hline Curso de Aperfeiçoame & 5 & 12,5 & 13 & 32,5 & 3 & 7,5 & 3 & 7,5 & 10 & 25 & 6 & 15 & 40 & 100 \\
\hline Dados Estatísticos & 9 & 22,5 & 8 & 20 & 8 & 20 & 5 & 12,5 & 6 & 15 & 4 & 10 & 40 & 100 \\
\hline E-mails & 21 & 52,5 & 12 & 30 & 2 & 5 & 1 & 2,5 & 1 & 2,5 & 3 & 7,5 & 40 & 100 \\
\hline Grupos d & 11 & 27,5 & 10 & 25 & 5 & 12,5 & 3 & 7,5 & 7 & 17,5 & 4 & 10 & 40 & 100 \\
\hline Internet & 32 & 80 & 4 & 10 & 0 & 0 & 2 & 5 & 0 & 0 & 2 & 5 & 40 & 10 \\
\hline Jornais d & 9 & 22,5 & 15 & 37,5 & 6 & 15 & 4 & 10 & 2 & 5 & 4 & 10 & 40 & 100 \\
\hline Legislaçã & 6 & 15 & 11 & 27,5 & 8 & 20 & 4 & 10 & 7 & 17,5 & 4 & 10 & 40 & 10 \\
\hline Livros E & 27 & 67,5 & 10 & 25 & 0 & 0 & 2 & 5 & 1 & 2,5 & 0 & 0 & 40 & 100 \\
\hline Livros Nac & 23 & 57,5 & 10 & 25 & 4 & 10 & 3 & 7,5 & 0 & 0 & 0 & 0 & 40 & 100 \\
\hline Manuais & 9 & 22,5 & 6 & 15 & 11 & 27,5 & 8 & 20 & 2 & 5 & 4 & 10 & 40 & 11 \\
\hline Mater & 8 & 20 & 8 & 20 & 7 & 17,5 & 5 & 12,5 & 7 & 17,5 & 5 & 12,5 & 40 & 100 \\
\hline Normas e & 8 & 20 & 12 & 30 & 6 & 15 & 2 & 5 & 5 & 12,5 & 7 & 17,5 & 40 & 100 \\
\hline Obras de Referências (índ & 20 & 50 & 10 & 25 & 4 & 10 & 1 & 2,5 & 0 & 0 & 5 & 12,5 & 40 & 10 \\
\hline Originais fornecidos pelo autor & 15 & 37,5 & 12 & 30 & 1 & 2,5 & 4 & 10 & 5 & 12,5 & 3 & 7,5 & 40 & 10 \\
\hline $\begin{array}{l}\text { Papers de } \\
\text { ferências }\end{array}$ & 23 & 57,5 & 8 & 20 & 5 & 12,5 & 1 & 2,5 & 1 & 2,5 & 2 & 5 & & \\
\hline Patentes & 5 & 12,5 & 8 & 20 & 6 & 1 & 3 &, 5 & 15 & 37,5 & 3 & 7,5 & 40 & 14 \\
\hline $\begin{array}{l}\text { Publicações Govername } \\
\text { Nacionais e Estrangeira }\end{array}$ & 4 & 10 & 13 & 32,5 & 4 & 10 & 5 & 12,5 & 9 & 22,5 & 5 & 12,5 & 40 & 100 \\
\hline Relatórios de Pesquisa & 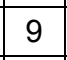 & 22,5 & 14 & 35 & 4 & 10 & 6 & 15 & 3 & 7,5 & 7 & 10 & 40 & 100 \\
\hline Relatórios não Publicados & 2 & 5 & 6 & 15 & 8 & 20 & 7 & 17,5 & 11 & 27,5 & 6 & 15 & 40 & 100 \\
\hline Reuniões Acadêmico-Cient & 15 & 37,5 & 9 & 22,5 & 4 & 10 & 5 & 12,5 & 3 & 7,5 & 4 & 10 & 40 & 100 \\
\hline Revisões de Literatura & 16 & 40 & 17 & 42,5 & 2 & 5 & 0 & 0 & 1 & 2,5 & 4 & 10 & 40 & 100 \\
\hline Revistas Técnico-Científicas Estrangeiras & 26 & 65 & 10 & 25 & 1 & 2,5 & 0 & 0 & 2 & 5 & 1 & 2,5 & & 100 \\
\hline Revistas Técnico-Científicas Nacionais & 24 & 60 & 10 & 25 & 2 & 5 & 0 & 0 & 1 & 2,5 & 3 & 7,5 & 40 & 100 \\
\hline Teses / Dissertações / Monografias & 23 & 57,5 & 9 & 22,5 & 5 & 12,5 & 0 & 0 & 2 & 5 & 1 & 2,5 & 40 & 100 \\
\hline Visitas Técnicas & 7 & 17,5 & 15 & 37,5 & 2 & 5 & 4 & 10 & 5 & 12,5 & 7 & 17,5 & & 100 \\
\hline
\end{tabular}

Em relação à freqüência às bibliote- tivo, e isso pode estar relacionado às facilicas virtuais, disponíveis para consulta esdades que esse tipo de biblioteca pode pecialmente via Internet, além de outras redes de computadores, comparando-se os índices de freqüências a estas, nota-se que o seu uso pelos pesquisadores é significaapresentar no processo de busca e recuperação da informação. Não respondeu a essa questão $7,5 \%$ dos pesquisados, os quais podem estar revelando que também 
não as utilizam com freqüência. Contudo, quando se toma o índice de $70 \%$ referente ao número de pesquisadores que as freqüentam mais de 7 vezes ao mês, percebe-se que este é o canal mais utilizado para buscar informações atualizadas.

Diz Souza (2003, p. 135) "A comunicação interpessoal tornou mais ágil e foi ampliada a disponibilidade de informação pelo acesso às bibliotecas virtuais de todo o mundo".

Nesse contexto, a Internet tem tido um papel fundamental na comunicação, por ser um veiculo rápido e com cobertura universal. A realidade é que novas tecnologias de informação vêm proporcionando profundas transformações nos procedimentos de produção, transmissão e uso da informação. Cada vez mais a informação está sendo disponibilizada na forma eletrônica, agregando constantemente novas fontes de informações bibliográficas, além do texto, da imagem, do som e dos dados numéricos. (GIRALDES, 2001, p. 30)

Os resultados obtidos sobre a utilização das bibliotecas dos colegas podem ser considerados baixos em relação aos índices de freqüências às demais bibliotecas, pela relevância da troca de informações entre os próprios pesquisadores dentro da UEPG. Os pesquisados freqüentam mensalmente a biblioteca do colega 1-2 vezes ao mês - $42,5 \%$; $3-4$ vezes ao mês - 5\%; 5-6 vezes ao mês - $0 \%$ e mais de 7 vezes por mês $-2,5 \%$. Entretanto, $32,5 \%$ deles afirmam que nunca necessitam das biblio- tecas dos colegas e $17,5 \%$ dos pesquisadores não responderam à questão.

Devido ao aumento na freqüência mensal a outros tipos de bibliotecas, entre as quais: bibliotecas de outras instituições, bibliotecas de colegas e bibliotecas virtuais (internet), julgou-se importante solicitar aos pesquisadores que opinassem sobre 0 grau de atualização das coleções do Sistema de Bibliotecas da UEPG. A esse respeito, $30 \%$ dos pesquisados consideram a coleção do Sistema de Bibliotecas da UEPG regular, $12,5 \%$ boa e $42,5 \%$ ruim. Considera a coleção excelente $2,5 \%$ e $10 \%$ respondeu desconhecer o grau de atualização da coleção, num universo em que $2,5 \%$ preferiu não responder à questão.

As informações obtidas nessa questão permitem inferir o motivo da alta freqüência de uso das bibliotecas virtuais pelos pesquisadores. Segundo Granja (1978, p. 18) "As bibliotecas universitárias brasileiras não estão preparadas para atender as exigências do momento em termo de ensino e pesquisa".

Em relação à questão: Se o pesquisador recorre ao pessoal bibliotecário do Sistema de Bibliotecas da UEPG, $45 \%$ dos pesquisadores responderam que sim, justificando que facilita na procura das informações desejadas e no contato com as fontes de informação por considerar o pessoal bibliotecário qualificado e preparado. Não costuma recorrer aos bibliotecários 50\% dos pesquisados os quais relataram que 
utilizam outras instituições que têm Periódicos do Portal Capes e que o Sistema de Bibliotecas carece de mais Bancos de Dados. Não respondeu à questão $5 \%$ dos pesquisados, o que pode comprovar a afirmação de Prazeres (1989, p. 57):

[...] usuários de informação científica, principalmente pesquisadores acadêmicos além de fazerem pouco uso dos sistemas de informação, não são inclinados a delegar aos bibliotecários a tarefa de buscar de informação para atender necessidades mais complexas e difíceis de serem definidas. Nesses casos, preferem realizá-las pessoalmente obtendo na maioria das vezes resultados mais rápidos e bem sucedidos.

Sobre a questão: Quando você necessita de uma informação para realizar uma pesquisa você consulta: seu arquivo pessoal; colegas do mesmo departamento; colegas de outros departamentos; colegas de outras instituições; bibliografias citadas em obras sobre o assunto (livros, periódicos); catálogos/materiais do Sistema de Bibliotecas da UEPG ou catálogos/materiais de outras bibliotecas. Por ordem de prioridade ficou estabelecido: 1 - consulta o arquivo pessoal; 2 - consulta bibliografias citadas em obras sobre o assunto (livros, periódicos); 3 - consulta colegas de outras instituições; 4 - consulta colegas do mesmo departamento; 5 - consulta catálogos/materiais do Sistema de Bibliotecas da UEPG; 6 - consulta colegas de outros departamentos e por último 7 - consulta catálogos/materiais de outras bibliotecas. $O$ que se nota é que mais uma vez o pesquisador tem preferido contactar primeiro colegas de outras instituições e posteriormente colegas do próprio departamento ou da própria instituição. Observa-se certa fragilidade de comunicação com os colegas e reduzido recurso à biblioteca. Parece que os pesquisadores não acreditam que possam encontrar o que necessitam para suprir suas necessidades informacionais.

O estudo procurou também tornar conhecida a freqüência com que se busca recursos e serviços de informação disponíveis no Sistema de Bibliotecas da UEPG.

Para isso foram relacionados os serviços de: empréstimo domiciliar; empréstimo interbibliotecas; curso de orientação bibliográfica; acesso on-line a base de dados e comutação bibliográfica, em que se deveria atribuir a cada um dos serviços relacionados o grau de utilidade cuja variação era de muito útil a não útil. Dos pesquisados $45 \%$ consideram o empréstimo domiciliar muito útil. Enquanto $40 \%$ não utiliza o serviço de empréstimo interbibliotecas, que é uma fonte para recuperação da informação. Talvez o que falta neste caso seja uma melhor divulgação dos serviços, ou a segmentação do público como alguns dos pesquisadores mencionaram.

Com relação à questão - Se o Sistema de Bibliotecas da UEPG tem contribuído como um canal de comunicação científica para os pesquisadores da UEPG, $57,5 \%$ responderam afirmativamente, justi- 
ficando que têm conseguido acesso a informações além de orientações e que, apesar das dificuldades da UEPG não se pode negar a eficiência do trabalho dos seus bibliotecários.

Dos pesquisados $42,5 \%$ responderam que não tem contribuído justificando que não há regularidade nas assinaturas dos periódicos; há pouca divulgação dos produtos e serviços do Sistema de Bibliotecas da UEPG; o Sistema de Bibliotecas é voltado mais para a graduação; e não há acesso aos Periódicos do Portal CAPES (a disponibilidade de acesso ocorreu a partir de janeiro de 2005).

Ao procurar estudar os hábitos dos pesquisadores da UEPG com relação à obtenção de informações, incluiu-se uma questão referente à importância que eles atribuem aos serviços necessários para o seu melhor desempenho na pesquisa os quais poderiam atender suas necessidades informacionais. Foi solicitado que o pesquisador atribuísse um grau de importância, em uma escala de mais importante a sem importância.

$O$ acesso on-line a base de dados foi considerado o mais importante para $75 \%$ dos pesquisadores, enquanto publicações de bibliografias por assuntos foram julgadas importantes por $67,5 \%$ dos pesquisadores.

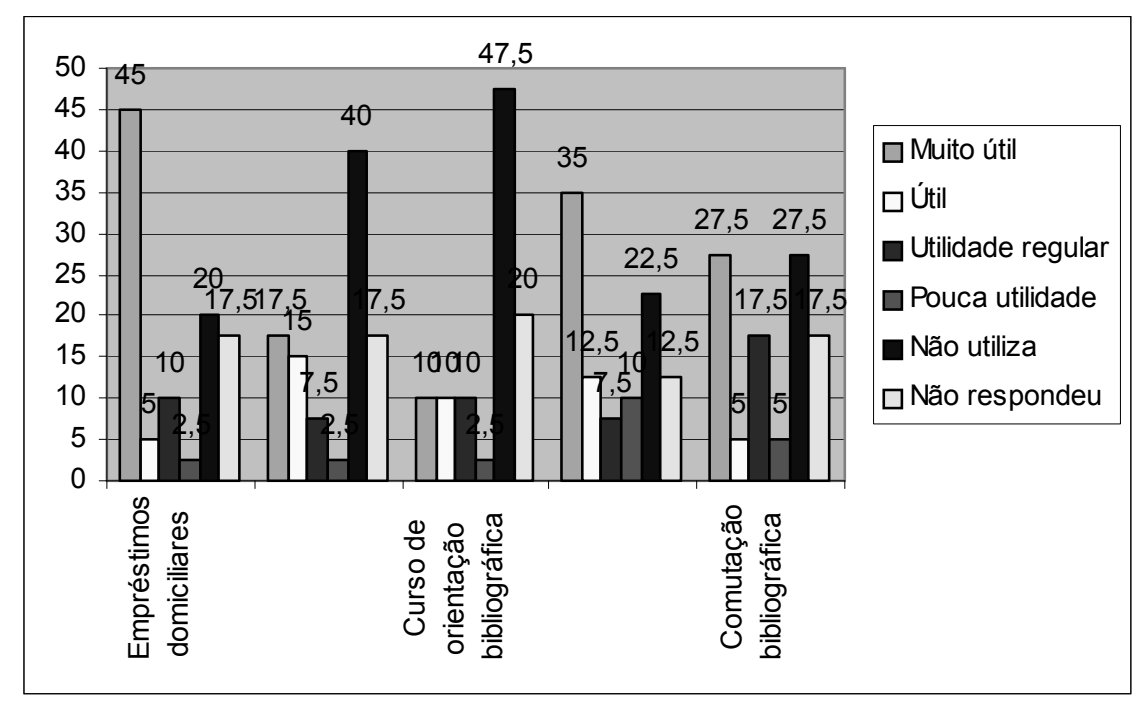

Gráfico 2 - Recursos de informação oferecidos pelos Sistemas de Bibliotecas da UEPG - 2004

No que se refere ao serviço de tradução, o estudo evidenciou uma contradição entre os pesquisados. Considerou-a importante $45 \%$, enquanto $20 \%$ a consideraram de pouca importância. Diante dessa resposta, acredita-se que o assunto deva ser mais bem investigado para saber qual serviço realmente o pesquisador necessita e 
se a biblioteca deve oferecê-lo, visto que $70 \%$ dos respondentes são doutores e pressupõe-se que tenham domínio de alguns idiomas, principalmente o inglês, requisito básico. Com isso os resultados do Gráfico 2 e da Tabela 4 poderão servir como base para a avaliação dos serviços existentes e também para a viabilidade de implantação de outros serviços.

\section{CONCLUSÃO}

O estudo evidenciou que a internet se constitui a fonte de informação dos pesquisadores $(80 \%)$ da UEPG considerada muito útil, seguida por livros estrangeiros
$(67,5 \%)$ e revistas técnico-científicas estrangeiras $(65 \%)$.

No que se refere ao uso da biblioteca como fonte de recuperação da informação, verificou-se que $70 \%$ dos pesquisadores utilizam mais de 7 vezes ao mês as bibliotecas virtuais (internet), enquanto o Sistema de Bibliotecas da UEPG é utilizado por $10 \%$ mais de 7 vezes ao mês.

Sobre o pesquisador recorrer aos bibliotecários da UEPG, $45 \%$ dos pesquisadores responderam que sim; $50 \%$ que não e $5 \%$ preferiram não responder a questão.

Tabela 4 - Serviços que poderão atender as necessidades dos pesquisadores -2004

\begin{tabular}{|c|c|c|c|c|c|c|c|c|c|c|c|c|}
\hline \multirow{3}{*}{ SERVIÇOS } & \multicolumn{12}{|c|}{ GRAU DE IMPORTÂNCIA } \\
\hline & \multicolumn{2}{|c|}{$\begin{array}{c}\text { Muito } \\
\text { Importante }\end{array}$} & \multicolumn{2}{|c|}{ Importante } & \multicolumn{2}{|c|}{$\begin{array}{c}\text { Pouco } \\
\text { Importante }\end{array}$} & \multicolumn{2}{|c|}{\begin{tabular}{|c|} 
Sem \\
Importância
\end{tabular}} & \multicolumn{2}{|c|}{\begin{tabular}{|c|} 
Sem \\
Informação
\end{tabular}} & \multicolumn{2}{|c|}{ Total } \\
\hline & $n^{\circ}$ & $\%$ & $\mathrm{n}^{\circ}$ & $\%$ & $\mathrm{n}^{\circ}$ & $\%$ & $\mathrm{n}^{\circ}$ & $\%$ & $\mathrm{n}^{\circ}$ & $\%$ & $\mathrm{n}^{\circ}$ & $\%$ \\
\hline Acesso online a base de dados & 30 & 75 & 9 & 22,5 & 0 & 0 & 0 & 0 & 1 & 2,5 & 40 & 100 \\
\hline Acesso a indicadores estatísticos & 9 & 22,5 & 12 & 30 & 12 & 30 & 3 & 7,5 & 4 & 10 & 40 & 100 \\
\hline Artigos de revisão & 20 & 50 & 14 & 35 & 1 & 2,5 & 1 & 2,5 & 4 & 10 & 40 & 100 \\
\hline Circulação de periódicos & 26 & 65 & 11 & 27,5 & 1 & 2,5 & 0 & 0 & 2 & 5 & 40 & 100 \\
\hline Comutação bibliográfica & 15 & 37,5 & 17 & 42,5 & 5 & 12,5 & 1 & 2,5 & 2 & 5 & 40 & 100 \\
\hline Disseminação seletiva da informação & 4 & 10 & 22 & 55 & 7 & 17,5 & 1 & 2,5 & 6 & 15 & 40 & 100 \\
\hline Empréstimo interbibliotecário & 9 & 22,5 & 20 & 50 & 7 & 17,5 & 0 & 0 & 4 & 10 & 40 & 100 \\
\hline $\begin{array}{l}\text { Empréstimo por telefone, e-mail e } \\
\text { correio }\end{array}$ & 11 & 27,5 & 13 & 32,5 & 6 & 15 & 3 & 7,5 & 7 & 17,5 & 40 & 100 \\
\hline Fontes eletrônicas & 23 & 57,5 & 12 & 30 & 0 & 0 & 0 & 0 & 5 & 12,5 & 40 & 100 \\
\hline $\begin{array}{l}\text { Hemeroteca (recortes de jomais e } \\
\text { revistas) }\end{array}$ & 4 & 10 & 10 & 25 & 17 & 42,5 & 1 & 2,5 & 8 & 20 & 40 & 100 \\
\hline Indexação de artigos de periódicos & 21 & 52,5 & 13 & 32,5 & 2 & 5 & & 0 & 4 & 10 & 40 & 100 \\
\hline Levantamento bibliográfico & 19 & 47,5 & 20 & 50 & & 0 & 1 & 2,5 & & 0 & 40 & 100 \\
\hline Listas de novas aquisições & 19 & 47,5 & 16 & 40 & 1 & 2,5 & & 0 & 4 & 10 & 40 & 100 \\
\hline $\begin{array}{l}\text { Orientação formal e informal quanto } \\
\text { a: } \\
\text { a) divulgação dos trabalhos publi- } \\
\text { cados }\end{array}$ & 15 & 37,5 & 19 & 47,5 & 1 & 2,5 & 1 & 2,5 & 4 & 10 & 40 & 100 \\
\hline $\begin{array}{l}\text { b) estratégias de buscas em bases } \\
\text { de dados }\end{array}$ & 20 & 50 & 14 & 35 & 3 & 7,5 & 0 & 0 & 3 & 7,5 & 40 & 100 \\
\hline c) uso de fontes de referência & 11 & 27,5 & 22 & 55 & 3 & 7,5 & 0 & 0 & 4 & 10 & 40 & 100 \\
\hline $\begin{array}{l}\text { Palestras e conferências relaciona- } \\
\text { das a interesses dos pesquisadores }\end{array}$ & 9 & 22,5 & 22 & 55 & 3 & 7,5 & 0 & 0 & 6 & 15 & 40 & 100 \\
\hline $\begin{array}{l}\text { Publicações de bibliografias por } \\
\text { assuntos }\end{array}$ & 6 & 15 & 27 & 67,5 & 2 & 5 & 3 & 7,5 & 2 & 5 & 40 & 100 \\
\hline Serviço de tradução & 6 & 15 & 18 & 45 & 8 & 20 & 4 & 10 & 4 & 10 & 40 & 100 \\
\hline
\end{tabular}


Em relação aos critérios para a escoIha das fontes de informação, os pesquisadores demonstraram preferência pelas que oferecem respostas mais relevantes às suas necessidades de informação. Os critérios: escritas por autores conhecidos e serem recomendadas por pessoas de confiança foram considerados menos importante para os pesquisados.

Sobre a importância atribuída pelos pesquisadores aos recursos e serviços de informação que poderiam preencher suas necessidades informacionais, o acesso online a base de dados e circulação de periódicos foram considerados muito importantes respectivamente por $75 \%$ e $65 \%$ dos pesquisadores. Porém, ao atribuírem graus de utilidade às fontes de informação, banco de dados foi considerado muito útil por $47,5 \%$ dos pesquisadores. Enquanto $30 \%$ a consideraram útil.

Com relação ao colégio invisível pode-se afirmar a existência entre os pesquisadores da UEPG com os pesquisadores de outras instituições, já que $52, \%$ mantêm freqüentemente contato com pesquisadores de outras instituições nacionais e $37,5 \%$ freqüentemente com pesquisadores de instituições estrangeiras.

Dentre os principais obstáculos apontados pelos pesquisadores encontram-se a desatualização do acervo do Sistema de Bibliotecas da UEPG, inexistência de títulos importantes de periódicos, falhas nas coleções dos periódicos existentes, o não acesso aos Periódicos do Portal CAPES (acesso a partir de janeiro/2005) e a falta de divulgação dos serviços oferecidos pelo Sistema de Bibliotecas da UEPG.

\section{REFERÊNCIAS}

ANDREESSEN, M. Depois do vendaval. HSM Management, São Paulo, v. 27, n. 5, p. 52-58, 2001.

ARAÚJO, V.M.R.H. de. Estudo de canais informais de comunicação técnica: seu papel na transferência de tecnologia e na inovação tecnológica. Ciência da Informação, Rio de Janeiro, v. 8, n. 2, p. 79-100, 1979. Informação: instrumento de dominação e de submissão. Ciência da Informação, Brasília, v. 20, n. 1, p. 37-44, 1991.

BACK, H.B. What information dissemination studes imply concerning the dising of on-line reference retrieval-systems. Journal of the American Society for Information Science, v. 23, n. 3, p. 156-163, may/june 1972.

BETTIOL, E. M. Necessidades de informação na área de Biotecnologia Agropecuária no Brasil. . Ciência da Informação, Brasília, v. 19, n. 1, p. 3-11, jan./jun. 1990.

CHRISTOVÃO, H. T. Da comunicação informal à comunicação formal: identificação da frente de pesquisa através de filtros de qualidade. Ciência da Informação, Rio de Janeiro, v. 8, n. 1, p. 3-36, 1979.

DALLA ZEN, A. M. Canais, fontes e uso da informação científica: uma abordagem teórica. R. Bibliotecon \& Comum, Porto Alegre, v. 4, p. 29-41, jan./dez. 1989;

DIAS, C. A. Comunicação científica. 1999. Disponível em:

<http://www.geocities.com/claudiaad/comu nica.pdf>. Acesso em: 10 out. 2004.

FARIA, C. M. de S. A comunicação da informação científica e tecnológica: perspec- 
tivas de pesquisa. $R$ Bibliotecon Brasília, v. 14, n. 1, p. 39-49, jan./jun. 1986.

GARVEY, W. D. Communication: the essence of science. Oxford; Pergamon, 1979.

GIACOMETTI, M. M. Motivação e busca da informação pelo docente-pesquisador. Ciência da Informação, Brasília, v. 19, n. 1, p. 12-20, jan./jun. 1990.

GIRALDES, M. J. C. Papel do profissional da informação: necessidades de docentes/pesquisadores da Universidade Estadual de Londrina e o periódico científico eletrônico. 2001. Dissertação (Mestrado em Biblioteconomia) - Pontifícia Universidade Católica de Campinas, Campinas, 2001.

GRANJA, E. C. A. A Biblioteca universitária e sua contribuição para o desenvolvimento da pesquisa científica. $R$. Bras. Bibliotec. Doc., v.11, n.1/2, p.17-20, jan.jun. 1978.

GUEDES, M. G.; BARROS, A.T. Comunicação informal do corpo docente da Universidade Federal do Piauí. Trans-informação, Campinas, v. 5, n.1/3, p. 43-71, 1993.

GUIMARÃES, R. et al. A pesquisa no Brasil: parte2: desempenho. Ciência Hoje, Rio de Janeiro, v. 19, n. 10, p. 93-115, jun. 1995.

GUSMÃO, H.R. Processo de comunicação informal entre os docentes do Departamento de Documentação da Universidade Federal Fluminense. In: CONGRESSO BRASILEIRO DE BIBLIOTECONOMIA E DOCUMENTAÇÃO, 1987, Recife. Anais... Recife, 1987. p. 832-848.

KREMER, J. M. Avaliação de fontes de informação usadas por engenheiros. $R$. Bibliotecon. Brasília, v. 10, n. 2, p. 65-78, jul/dez. 1982.

MEADOWS, A. J. Comunicação científica. Brasília: Briquet de Lemos, 1999.
Avaliando o desenvolvimento da comunicação eletrônica. In: MUELLER, S.P.M.; PASSO, E.J.L. (Org.). Comunicação científica. Brasília: UNB, 2000.

MUELLER, S. P. M. O artigo científico como meio de comunicação primária do conhecimento científico: uma visão da literatura de tópicos importantes para o tema. In: ENCONTRO NACIONAL DE PESQUISA EM CIÊNCIA DA INFORMAÇÃO E BIBLIOTECONOMIA,1., 1994, Belo Horizonte. Anais... Belo Horizonte: UFMG, 1994.

A ciencia, o sistema de comunicação científica e a literatura científica. In: CAMPELLO, B. S.; CENDÓN, B. V.; KREMER, J. M. (Org.). Fontes de informação para pesquisadores e profissionais. Belo Horizonte: UFMG, 2000a. p. 21-34.

O periódico científico. In: CAMPELLO, B. S.; CENDÓN, B. V.; KREMER, J. M. (Org.). Fontes de informação para pesquisadores e profissionais. Belo Horizonte: UFMG, 2000b. p. 73-95.

PINHEIRO, L.V.R. Comunidades científicas e infra-estrutura tecnológica no Brasil para uso de recursos eletrônicos de comunicação e informação na pesquisa. Ciência da Informação, Brasília, v. 32, n. 3, p. set./dez. 2003.

PRAZERES, Y. M. P. da C. Busca da informação: comportamento dos docentes/pesquisadores da Universidade Estadual de Londrina. 1989. Dissertação (Mestrado em Biblioteconomia) - Pontifícia Universidade Católica de Campinas, Campinas, 1989.

RAMOS, M. G. Modelos de comunicação e divulgação científicas: uma revisão de perspectivas. Ciência da Informação, Brasília, v. 23, n. 3, p. 340-348, set./dez. 1994.

RODRIGUES, M. da P. L. ; VILAS BOAS, J.R.M. Canais de comunicação utilizados pelos pesquisadores da Universidade $\mathrm{Fe}$ deral do Maranhão. Ciência da Informação, 
Brasília, v.22, n.3, p.237-241, set./dez. 1993.

ROSEMBERG, D. S. A Leitura, os canais intermediários de informação na formação continuada de professores universitários. In: PROCEEDINGS XIX CONGRESSO BRASILEIRO DE BIBLIOTECONOMIA E DOCUMENTAÇÃO 1, 2000, Porto Alegre. Anais ... Porto Alegre, 2000.

SAMPAIO, M. da P. F. Comunicação cientifica fatores intervenientes e influentes: 0 ponto de vista dos pesquisadores do CCEN/UFPE. In: SEMINÁRIO NACIONAL DE BIBLIOTECAS UNIVERSITÁRIAS, 11., 2000, Florianópolis. Anais... Florianópolis: UFSC, 2000. 1 CD-ROM.

SOUTO, L. F. O leitor universitário e sua formação quanto ao uso de recursos informacionais. Biblios, ano 5, n. 17, p. 16-24, enero-marzo 2004. Disponível em: <http://wotan.liu.edu/dois/data/Articles/juljul jujy:2004:v:5:i:17:p:1288.html>. Acesso em: 10 fev. 2005.

SOUZA, M. da P. N. Efeitos das tecnologias da informação na comunicação de pesquisadores da Embrapa. Ciência da Informação, Brasília, v. 32, n. 1, p. 135-143, jan./abr. 2003.

TARGINO, M. G. Comunicação cientifica: uma revisão de seus elementos básicos. Informação \& Sociedade: estudos, João Pessoa, v. 10, n. 2, 2000. Disponível em: $<$ http://www.informaçãoesociedade.ufpb.br >. Acesso em: 08 mar. 2005.

WITTER, G.P. Pesquisa bibliográfica pesquisa documental e busca de informação. Estudos de Psicologia, Campinas, n. 1, p. 5-30, jan./jul. 1990.

\section{Ângela Maria de Oliveira}

Bibliotecária da Universidade Estadual de Ponta Grossa. Graduada em Biblioteconomia (UEL). Mestre em Biblioteconomia e Ciência da Informação (MINTER UFPR/PUCCAMP) amolivei@uepg.br

Ivani da Silva

Bibliotecária da Universidade Estadual de Ponta Grossa. Graduada em Biblioteconomia (UEL). Especialista em Uso Estratégico das Novas Tecnologias da Informação (Marília) ivsilva@uepg.br

Eunice Silva de Novais

Bibliotecária da Universidade Estadual de Ponta Grossa. Graduada em Biblioteconomia (UEL). Especialista em Marketing (UEPG) enovais@uepg.br

\section{Title}

Information channels used by the reserchers of the State University of Ponta Grossa (PR)

\begin{abstract}
This study aimed to identify the information channels used by the researchers of the State University of Ponta Grossa (UEPG) - Paraná to supply their information needs. The study, characterized as an exploratory research, had as data collection instrument the questionnaire, consisting of both open and closed format questions. The questionnaire was divided into three parts: the first one about the researcher profile, age group, professor category, academic title, work system; the second part was directed to the activities developed by the researches at UEPG, their work experience at the university (learning and research), among other things; the third section comprehended the information and the communication that embrace the researches' behavior concerning the information search for the development of their academic activities, the means that are used by
\end{abstract}


them to get up to date, and the contribution of the UPEG's Library System for their scientific communication. The questionnaire was sent electronically for the 161 researchers that are distributed in the following academic sectors of the university: Sector of Agrarian and Technology Sciences; Sector of Exact and Natural Sciences; Sector of Human Sciences, Letters and Arts; Sector of Juridical Sciences; Sector of Social Applied Sciences and Sector of Biological and Health Sciences. The study demonstrates that the researchers prefer the informal channels to acquire information. The Internet and the "invisible colleges", as well as the virtual libraries are more used than the UEPG's Libraries. It concludes that is necessary to update the scientific journals collection and also emphasizes the importance to improve the divulgation of the services that are offered by the UEPG's Libraries System.

\section{Keywords}

Information channels; Information needs; State University of Ponta Grossa (PR)

\section{Titulo}

Canales de información de los investigadores de la Universidad Estatal de Ponta Grossa (PR)

\section{Resumen}

Este estudio tiene como objetivo identificar los canales de información utilizados por los investigadores de la Universidad Estatal de Ponta Grossa (UEPG) - Paraná para que atiendan sus necesidades informacionales. Es un estudio de carácter exploratório, teniendo como instrumento de colecta de datos un cuestionario preguntas abiertas y cerradas, que fue dividido en tres partes: la primera referente al perfil del investigador, la edad, categoría docente, titulación y regimen de trabajo; el segundo, con las actividades desarrolladas por los investigadores en la UEPG, experiencia profesional en la institución (enseñanza e investigación), y otros; y el tercero, comprendendo información y comunicación que abrangió el comportamiento de los investigadores con relación a la búsqueda de la información necesaria a la realización de sus trabajos; los medios utilizados para la actualización de conocimientos y la contribución del Sistema de Bibliotecas de la UEPG en la comunicación científica de los investigadores, el cuestionario fue enviado electrónicamente a los 161 investigadores que están distribuídos en los siguientes sectores académicos de la UEPG: Sector de Ciencias Agrárias y de Tecnología; Sector de Ciencias Exatas y Naturales; Sector de Ciencias Humanas, Letras y Artes; Sector de Ciencias Jurídicas; Sector de Ciencias Sociales Aplicadas y Sector de Ciencias Biológicas y de la Salud. El estudio demostra que los investigadores utilizan más los canales informales, es decir que, la internet y el "colegio invisibles", así como las bibliotecas virtuales son más utilizadas que las Bibliotecas del Sistema de la UEPG. Es necesario, entonces, la actualización del acervo de periódicos, y la divulgación de los servicios ofrecidos por el Sistema de Bibliotecas de la UEPG.

\section{Palabras clave}

Canales de información; Necesidades informacionales; Universidad Estatal de Ponta Grossa (PR) 